\title{
Challenges and Changes Faced by Rural Superintendents
}

\author{
Marcia L. Lamkin \\ University of North Florida
}

This research study was designed to build grounded theory about the challenges faced by rural superintendents. Participating rural superintendents identified five areas that presented a challenge but that also applied to superintendents in other settings: school law, finance, personnel, government mandates, and district or board policies. Further, these superintendents identified challenges related specifically to the rural setting and to their lack of acculturation to the demands of rural school leadership. Focus group research conducted among rural superintendents in New York, Pennsylvania, and Tennessee indicated that the challenges of the rural superintendency were distinct enough to warrant some specialized preparation for such service

Our public school districts face a serious shortage of candidates for the superintendency (Cooper, Fusarelli \& Carella, 2000; NYSCOSS, 2000). Fewer candidates find attractive the role of school superintendent, and many school administrators now wait until the end of their careers before they venture into the superintendency (Glass, Bjork, \& Brunner, 2000; NYSCOSS, 2000). Further, many "middle managers” among public school administrators - for example, principals, curriculum directors, and associate superintendents - see vividly the daily stresses and difficulties in the role of superintendent and choose consciously to avoid those problems by not advancing their careers into the superintendency.

Rural school districts and their superintendents face specific obstacles that render service in such districts and roles less attractive than elsewhere. These obstacles include isolation, limited resources, and community resistance to change, and have persisted over time (Barker, 1985; Beckner, 1983; DeYoung, 1994; Sher \& Rosenfeld, 1977; Stephens \& Turner, 1988). Many Americans lack value or respect in general for "ruralness" (Haas, 1991; Herzog \& Pittman, 1999). Rural school superintendents seem to be relegated to the bottom rung of the administrative farm system (Jacobson, 1988b), and rural districts endure rapid and frequent turnover among superintendents in their service (Bryant \& Grady, 1989; Chance \& Capps, 1992; Grady \& Bryant, 1991a \& 1991b; Wilson \& Heim, 1985). The simple reality for rural school districts at the start of the $21^{\text {st }}$ century is that it is difficult to attract, reward, and retain school leaders.

This exploratory study sought to understand the challenges and changes in the role of the rural superintendent of schools. Seven focus group discussions were completed with nearly 60 rural superintendents in upstate New York, Pennsylvania, and Tennessee. Through their feedback and this analysis, the study aimed to develop an understanding of the challenges faced by superintendents in rural service. In confirmation of the issues raised in the literature, the results of this study revealed that practicing superintendents in rural areas have unique experiences in their practice that require specific training through content, instructional techniques, and connections to the field of practice.

Further, the issue of "ruralness" needs to be distinguished from the issue of "smallness" among school districts. Many small districts exist in suburban and urban settings, and they share some of the challenges of rural districts, such as difficulty to recruit and retain qualified teachers, transportation costs, and lack of central office staff or expertise. But there are challenges that are unique to the leadership of rural school districts. Only in rural districts does the superintendent find him or herself to be the sole (or almost) administrator, the only chief executive in the community, and often the only target of public criticism. These superintendents manage what is often the largest employer in the community and thus also bear sole responsibility for both success and failure in the school district and often in the community. Due to the nature of such rural communities, rural superintendents suffer a unique lack of privacy; they enjoy little private life and come under scrutiny for everything that they do both at school and in other settings. Unlike their suburban and urban colleagues, they enjoy no respite from the community's attentive eyes and ears.

Improved preparation and support for the role of superintendent could advance more potential candidates, could attract more qualified candidates, and could enable more new superintendents to succeed in their first several years of service. Such improvement, however, requires a better understanding of the problems and challenges faced by rural superintendents. 


\section{Methods and Data}

In order to learn more about the way that rural superintendents experienced the difficulties of their role and to discover the ways in which their issues were similar or different from the national findings, rural superintendents in three states were asked to discuss their role, their dilemmas, and the changes that they had experienced over time in the role of school superintendent.

Seven focus group interviews were conducted among 58 rural superintendents in upstate New York, Pennsylvania, and Tennessee in 2001 and 2002 (See
Table 1). These three states were selected for their ruralness and for differences in state policy on superintendent licensure, accountability, and funding for school districts. The superintendent associations in each of the three states assisted with the recruitment of participants for the focus groups and hosted the sessions during either state-wide or regional meetings. The criteria for participation were that the superintendent led or had led a district of less than 550 students in a non-urban setting. I did not select participants but welcomed each superintendent who volunteered for the focus groups.

Table 1

Focus Group Locations and Participants

\begin{tabular}{lcr}
\hline Group \# & State & \# Participants \\
\hline 1 & Tennessee (TN1) & 6 \\
2 & Tennessee (TN2) & 14 \\
3 & Tennessee (TN3) & 3 \\
4 & New York (NY1) & 5 \\
5 & New York (NY2) & 5 \\
6 & New York (NY3) & 1 \\
7 & Pennsylvania (PA1) & 14 \\
8 & Pennsylvania (PA2) & 10
\end{tabular}

During these seven focus group discussions, I concentrated on the challenges and dilemmas that occupy most of the rural superintendents' time and energy, particularly new rural superintendents, and on changes to those challenges and dilemmas. New superintendents were defined as those who have served in the role less than three years. The goal for these focus group interviews was to hear from the "front lines" about the challenges of the work.

All the focus group interviews used a standard protocol of questions and were conducted according to Krueger and Casey's (2000) recommended approach. The core questions in the protocol were:

- What were the primary problems and challenges that you encountered as a new superintendent?

6

14

3

5

5

1

14

10

- What are the primary problems and challenges in your role now?

- How were you prepared or how did you prepare yourself for the superintendency?

- What recommendations would you make to improve the preparation and support of new superintendents?

- If money were no object, what new endeavors would you pursue?

I conducted each of the sessions alone, served as facilitator, and audio taped the interviews. The protocol of focus group questions followed the structure of my overall research questions about the challenges of the superintendency, about recent changes to those challenges, about the preparation that participants had completed, and about recommendations for future preparation and inservice programs. This study complements an on- 
going national study on the challenges and preparation needs of superintendents. The methodology, interview protocol questions, and data analysis were coordinated with the approach of the on-going national study, particularly for validity issues in interview questions and analysis and reliability issues in data collection and analysis. The focus group data were analyzed using Krueger and Casey's recommended methods for focus group data to identify themes and their prevalence within and across the groups and to contrast the views of superintendents among the three states.

The audiotapes of the sessions were transcribed and combined with the affiliated notes for analysis. I looked for related themes and patterns that emerged in the course of the conversations. The development of grounded theory employs established procedures for analysis. These procedures consist of "developing categories of information (open coding), interconnecting the categories (axial coding), building a 'story' that connects the categories (selective coding), and ending with a discursive set of theoretical propositions” (Creswell, 1998, p. 150). Results of the data analysis were then examined in the light of current research and literature about the superintendency and rural schools. There were four types of limitations inherent in the design of this study: location, similarity of background and training among participants, familiarity among the participants at specific locations, and reliance on memory of distant events. These limitations were counteracted to some degree by carefully structured prompts and by informed selection of settings for the focus group discussions.

This article presents the results of the analysis in relation to challenges in the work of the superintendent and changes to those challenges and compares those results to specific pieces from the literature review in order to address the challenges and dilemmas facing the rural school superintendent.

\section{Results}

Current conditions that prevail in our public schools - increased accountability for academic achievement, increased parent and community participation, increased media attention - have created visible and escalating challenges for superintendents. Greenfield (1995) posited that the work of school superintendents differs from the work of other chief executive officers in "the uniquely moral character of schools" (p. 61), the nature of the school staff as educated and independent, and the stormy context of schools in general that threatens the stability of the work of education.
Various authors have argued in recent years that the work of rural superintendents presents the same complexities as the work of school superintendents in other settings. Chance (1999) asserted that the work of the rural superintendent was just as filled with conflict, politics, and community input as the work of any superintendent. Earlier, both Leithwood and Montgomery (1986) and Manasse (1985) had written that superintendents had to serve as effective leaders and had to achieve district goals no matter the size or location of the district in which the superintendents served. Stephens and Turner (1988) further stated that:

What rural superintendents do, the activities and functions they engage in, the roles they perform, and the public and professional expectations about the position differ only in degree, not in substance or mode of operation, from their urban or suburban counterparts. (p. 26)

The results of this study yielded similar findings that rural superintendents faced challenges similar to the challenges faced by school leaders in other contexts - but also showed ways that the context shaped some challenges and raised others for these rural superintendents.

In this study, the challenges voiced by these rural superintendents in upstate New York, Pennsylvania, and Tennessee and the changes that have occurred to those challenges fell into two distinct categories. First, these superintendents spoke frequently about challenges related to their lack of adequate training for specific tasks and skills. Second, these superintendents spoke about challenges related specifically to the rural environment and to the lack of acculturation to the setting and expectations of the rural superintendent. Foremost among the challenges of the rural environment raised by the superintendents in this study were the close-knit relationships among life-long residents and the prevalence of emotional responses to considerations for change in those communities.

With the exception of technology, an issue that appeared only during the conversation about changes, all areas of change differed from earlier challenges in scale and intensity rather than in substance. Because so many of the participants were relatively new to the role of rural superintendent, this study does not provide adequate information to compare challenges for new superintendents to the challenges for experienced and seasoned superintendents. However, nearly half the participants had 10 years or more experience in the role of superintendent and could 
speak readily of the changes they had witnessed during their career in the position.

\section{Lack of adequate training in specific areas}

The literature on the rural superintendency contained many pieces of advice to meet the challenges of the role. Five areas - school law, finance, personnel, government mandates, and district or board politics - surfaced in each of the focus groups during our discussion of challenges and changes, and one additional area - technology appeared only during the discussion about recent changes but drew almost universal agreement among participants.

These six areas of inadequate training relate to challenges in the role of the superintendent in general and to challenges based on the changing field of education rather than to challenges based solely on the rural environment of the work of rural superintendents. That is, these findings could be applied to superintendents in any setting, not simply to those in rural school districts.

Participating rural superintendents voiced the challenge of school law, especially in the recent realm of potential litigation. One superintendent from New York stated that because "everybody wants to litigate, [superintendents] always have that on the back burner" (Table 1, NY2). This continuous watchfulness, the need for increased understanding of legal details, and a familiarity with due process presented a challenge of inadequate training for both rural superintendents and superintendents in general.

These rural superintendents discussed the challenge of finance, including the issue of building projects, with particular attention to the changes in politics, processes, and responsibilities of school finance. Focus group discussions revealed inadequate training for budget building, financial planning, capital projects, and state and federal financial procedures. A New York superintendent noted, "The financial piece [is the greatest challenge] (NY2)!”

Rural superintendents in Tennessee discussed a financial challenge specific to the system in their state, the home rule charter, which required school districts to request permission from the county government for each purchase above $\$ 50,000$ for the school year. This specialized method to finance rural schools in Tennessee appeared to generate confusion and frustration among even experienced superintendents. One Tennessee participant state, We had to deal with a home rule charter... for the purpose of controlling the budget, and [the County has] done a fabulous job of doing that... We not only go [to the County for permission] once, we go twice; we go three times; we go four times. For the same request, the same money! Anything over $\$ 50,000$ we must go back to [the County Commission]. (TN1)

Personnel and contract management, including the changing focus on the power of unions, surfaced as a challenge among these rural superintendents. Advice to rural superintendents (Holmes, 1991; Jacobson, 1988a; Keeney \& Devaney, 1982; Leach, 1991; Tagg, 1982; Tift, 1990; Wallin, 1999) includes the need to maintain effective time management in the face of diverse responsibilities and to manage effective teacher recruitment, induction, and retention. Rural superintendents voiced a lack of adequate training in the process of negotiating with employer organizations, in removing or retaining appropriate staff, and in dealing daily with union representatives. Speaking about the challenge of relations with unions in the district, one superintendent in Pennsylvania said, "Our teachers who are the closest to the parents - campaign against change, tell the parents that it's bad for the kids. And [the teachers] have the closer contact with those parents!”

Rural superintendents also noted the challenge of state and federal regulations and procedures, with special attention to the recent increase in mandates and paperwork and to rapid or unexpected changes to such regulations. Superintendents in New York, especially, noted the increased reporting requirements and the lack of timely notification about reporting changes. They felt "blind-sided" by new reports or by changes to the requirements for data collection. One superintendent at the annual superintendents' meeting in Tennessee said the "the things that we've been talking about this week I think have caught all of us, whether we're new or been around, they've caught all of us [off guard] (TN2)." While this finding corresponds to the literature about superintendents and rural superintendents, a related finding does not: A significant portion of the literature (Coleman \& LaRocque, 1988; Crowson \& Glass, 1991; Cuban, 1984; Musella \& Leithwood, 1988; Peterson, 1984; Peterson, Murphy, \& Hallinger, 1987) predicted a shift in the work of superintendents toward a focus on individual student achievement, but none of the superintendents who participated reported such a change. On the contrary, rural superintendents in all seven focus groups expressed resentment at the imposition of standards for student achievement by state and federal authorities and described a variety of ways in which they delegated the oversight and responsibility for 
curriculum and student achievement to building level staff.

Many rural superintendents discussed the challenge of district politics and board relations, with some talk about the change in the nature of boards, increased shared decision-making, and the demands of continuous communication. These issues concerned many of the participating superintendents - and affected all superintendents, not just rural superintendents - because the public battles between superintendents and boards presented a negative picture of the role of superintendent that further eroded the pool of candidates for the position. A Pennsylvania superintendent commented, "The Board is central, not just when [we're] new. [We] have to help them understand the rules, the requirements (PA1).”

Rural superintendents in Tennessee again discussed at length a change to district politics and board relations specific to their state system: the change from popularly elected superintendents to board-appointed superintendents. The shift from elections to appointments changed completely the superintendents' status with boards of education and in communities. "I was elected, popularly elected for three consecutive times and then I was appointed when the state law changed," noted on superintendent from Tennessee (TN2). Rather than serving as elected community representatives, appointed superintendents became additional employees, "hired guns” for school boards.

These rural superintendents raised only one issue as a recent change that had not been a challenge earlier in their service, the issue of the use of technology. Rural superintendents discussed technology as a tool to teach, to manage information, and to provide an accurate and rapid path to district accountability. "[Technology] makes us have to be more knowledgeable in assessment tools, statistical process, although the first few years as a superintendent, I never even used [technology] (TN3).” Especially among those rural superintendents who were nearing the end of their careers and who had trained many years before their current service, technology presented a challenge for which they had received no preparation at all; this challenge would again apply to all superintendents, not only to rural superintendents.

\section{Rural environment}

The second major group of challenges voiced by these rural superintendents related to the rural setting in which they served: the need to be a "jack of all trades," the demands of the small rural community, the need to market effectively across the school district and community, and the increased level of personal accountability. Rural superintendents who participated in these focus group interviews discussed at length and with visible frustration their lack of specialized guided contact and experience with rural communities and school districts.

Based on the descriptions of early years of service and on the discussions about changes to the role over time, the work of the interviewed rural superintendents presented the same complexities as the work of school superintendents in other contexts. However, one area of discussion among the participating rural superintendents represented a contradiction to the literature about the central role of the school superintendent. Certain literature about the superintendency described a conflict between the superintendent as leader and the superintendent as manager (Crowson \& Glass, 1991; Glass, 1991). These rural superintendents expressed no such conflict; all made it clear that they wanted to lead but were forced to manage.

Much of the literature about the superintendency has implied that service to rural schools is easier than service to larger or more cosmopolitan districts, offering advice to rural superintendents that reduced their leadership to a simple checklist (see, for example, Holmes, 1991; Jacobson, 1988a; Keeney \& Devaney, 1982; Leach, 1991; Tagg, 1982, Tift, 1990; Wallin, 1999). In practice, service in rural school districts appears to fall at the bottom end of the "pecking order": superintendents new to the role often were encouraged to "begin" in rural districts and subsequently work their way "up" to suburban and urban districts. Even the educational consultants who assist districts to hire superintendents noted that rural districts were "a good place to start" (Silky, 2003). But rural districts are not easier to manage. On the contrary, given the lack of administrative support and their more limited fiscal resources, rural districts may actually be more difficult to manage, thus compounding the challenges for new superintendents.

Rural superintendents in all three states and nearly every focus group interview used the same phrase to describe their work: "jack of all trades." In a variety of ways, they talked at length about the speed and diversity of their tasks, the level of personal accountability, the difficulties of time management, and the constant interruptions to their work, all stemming from their service in the rural setting. "It's like putting a puzzle together," said one rural superintendent (TN2). "It's like juggling ten balls at once,” said another (NY2). A Pennsylvania superintendent elaborated: "I have to handle transportation, contracts, building facilities, the work of the Board as opposed to the work of educating children... I wasn't prepared for the conflict that goes 
along with all the diverse tasks and issues that I faced (PA2)." These rural superintendents noted over and over again that they did not have enough staff or enough assistance in central office or in school buildings to delegate tasks away from their own desks. If they didn't complete a task, then students went without something.

Rural superintendents also talked in detail about their relationships in the rural community, their personal visibility, and the importance of their involvement in the local community as a whole. Rural communities preclude many opportunities for privacy and for confidentiality, and a number of these rural superintendents complained that their districts operated on emotionalism and gossip. The participating rural superintendents expressed the anxiety that they are too visible in their roles and their communities and at the state levels. "When you're in a small district, people can put their hands on you. They can talk to you. They can make their judgments based on what they see and what they know and how your behavior - what you say is really what you do (NY1)." That is, rather than accept the advice in the literature to be more visible and more involved, these rural practitioners voiced the need to retreat from the levels of exposure that they suffered both locally - at school and in their communities and in the face of increased scrutiny by distant government agencies.

Two superintendents, one in Tennessee and one in Pennsylvania, had entered educational administration from commercial sectors. These rural superintendents believed that the ability to market programs and initiatives in the rural setting formed the basis for successful service in rural school districts. Especially in rural districts where staff must assume new roles, where students must master skills unfamiliar to their parents, and where boards may not agree with mandates from the state and federal governments, the ability to market could represent a strong asset for the rural superintendent. On the other hand, superintendents who could not effectively market change or respond to new mandates probably could not succeed in the role of rural school leader.

Rural superintendents in all three states talked openly about the increased focus on academic and financial accountability in their work. Although many of the participants who expressed this challenge punctuated their remarks with humor, they made it clear that rural superintendents felt intense personal pressure to be accountable for the financial success of their districts and the academic success of their students.

\section{Discussion}

\section{Conclusions}

In a careful review of all the findings in this research, I can draw three primary conclusions about the challenges facing rural superintendents and how their role is changing. First, the premise that the role of rural school superintendent has become increasingly difficult may be the direct result of increased demands and decreased assistance. That is, the rural superintendent now struggles to do more with less. As with many public service roles, the rural superintendent has been thrust into a more visible and more accountable position: more media coverage, more accountability for test results, and more responsibility for finance. All these factors contribute to greater stress in the role. Concurrently, due to cost-saving measures in many small rural districts, the rural superintendent has less assistance to complete key tasks and must thus complete those tasks himself. Complicating this increased gap between demands and resources is the fact that rural school districts may have had to reach deeper into the pool of licensed candidates and tap administrators with less training and experience than in earlier years. That is, due to the pervasive shortage of qualified candidates for positions in educational administration, rural districts have more difficulty recruiting and retaining skilled administrators. This conclusion from the findings in this research correlates directly to assertions in the literature that rural school districts at the start of the $21^{\text {st }}$ century have difficult time attracting, rewarding, and retaining school leaders.

The most obvious solution to increased demands and decreased assistance may be the consolidation of rural districts into larger districts with greater resources and additional staff support. However, the simple logistics of geographic distance preclude this solution to the problem. Instead, rural districts need to examine the application of increased support systems, including web-based training and support systems and networking for rural superintendents. Existing literature (Holmes, 1991; Jacobson, 1988a; Keeney \& Devaney, 1982; Leach, 1991; Tagg, 1982; Tift, 1990) advocates establishing networks among small rural school district leaders to help handle the stressful working conditions, long hours, and lack of privacy. However, in a point of departure from the literature about visibility and involvement, participating superintendents expressed the anxiety that they were too visible in their roles.

Second, apparent changes to the challenges of the rural superintendency are not generally matters of substance, but primarily issues of scale and intensity. 
When these rural superintendents explained the "changes" to their dilemmas, those changes amounted to faster, deeper, longer, and more public versions of the same dilemmas with which superintendents were originally faced. For example, rural superintendents in the focus groups in all three states noted increased difficulty with the power and function of employment associations. However, such associations have long existed, long served as "watchdog" groups, and long made demands. The perceived "change" involves the development of more vocal, more visible, and persistent rural union voices.

Third, the challenges of rural service are different enough to warrant some specialized training for service to rural districts. The burden of being the only administrator in the central office - sometimes in the district - plus the demands of the closely-knit rural community and the calls for personal accountability render service to rural districts distinct from service to suburban or urban districts, where the superintendent would enjoy many layers of administrative assistance and separation from daily classroom and community concerns. Existing literature described specific obstacles that face rural schools and their superintendents and that render service in such districts and roles less attractive than service in other settings. These obstacles included isolation, limited resources, and community resistance to change (Barker, 1985; Beckner, 1983; DeYoung, 1994; Sher \& Rosenfeld, 1977; Stephens \& Turner, 1988). While rural superintendents have for many years concerned themselves with the success of their students, both state and federal governments now rank these small isolated schools against larger schools with more resources and more choices. Rural superintendents thus perceive a change in the level of their personal accountability.

\section{Recommendations}

This research has yielded three sets of recommendations. First, practicing rural school superintendents need to re-emphasize the positive aspects of their role and the connections between the role and their commitment to equitable opportunities in education for all students across the United States. As role models for their administrative teams, these rural superintendents need to emphasize the rewards of their service.

Next, practitioners who currently serve in the field, members of professional organizations, and agents of state education departments all need to agree to work together and to rethink programs of preparation and ongoing support with respect to the changing field and with attention to the differences among types of role and locale. In order to facilitate such meetings and discussions among the "stakeholders" in such programs, advisory councils or stakeholder partnerships may need to be formally created. The New York State Education Department, for example, has taken a lead role to effect such changes for school leaders in New York State and will form partnerships to review, evaluate, and reform existing programs or to create new ones.

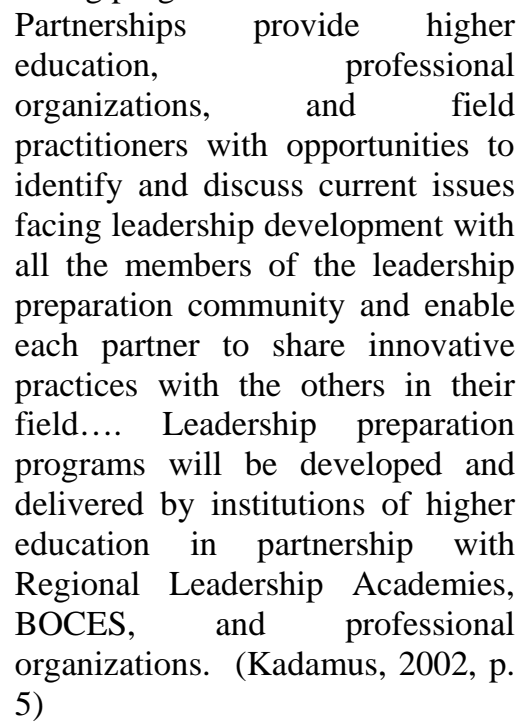

Once this process has been implemented and refined in New York State, other states may find the model useful in the assessment and reform of preparation and continued education for school administrators, especially for superintendents.

Finally, school board associations need to take a lead role to correct the problems created by school board misinformation and misbehavior and to provide information about ways to support and protect skilled superintendents so that rural school districts can attract and retain school leaders.

\section{Future research}

The research in this study was preliminary and warrants continuation and expansion: This study should be replicated in other rural locations in order to test the validity of my conclusions and to expand the discussions of reform to programs of preparation. Further, longitudinal studies of preparation specifics and success in educational administration should be initiated immediately and followed carefully across the next two decades. Rather than rely on the memories of administrators who may have trained two decades before - as this research team did researchers need to begin the study at the point of preparation and follow participants into their careers in rural school districts. 


\section{References}

Barker, B. O. (1985). A description of rural school districts in the United States. The Rural Educator, 3(6), i.

Beckner, W. (1983). The case for smaller schools. Bloomington, IN: Phi Delta Kappan Foundation.

Bryant, M. T., \& Grady, M. L. (1989). Superintendent turnover in rural school districts. Educational Considerations, 16(1), 34-36.

Chance, E. W. (1999). The rural superintendent: Succeeding or failing as a superintendent in rural schools. In D. M. Chalker (Ed.), Leadership for rural schools: Lessons for all. Lancaster, PA: Technomic Publishing Co.

Chance, E. W., \& Capps, J. L. (1992). Superintendent stability in schools. National Forum of Educational Administration and Supervision Journal, 9(2), 23-32.

Coleman, P., \& LaRocque, L. (1988). Reaching out: Instructional leadership in school districts. Peabody Journal of Education, 65(4), 60-89.

Cooper, B., Fuscarelli, L., \& Carella, V. (2000). Career crisis in the school superintendency? Arlington, VA: American Association of School Administrators.

Creswell, J. W. (1998). Qualitative inquiry and research design: choosing among five traditions. Thousand Oaks, CA: Sage.

Crowson, R. L., \& Glass, T. E. (1991, April). The changing role of the local school district superintendent in the United States. Paper presented at the annual meeting of the American Educational Research Association, Chicago.

Cuban. L. (1984). Transforming the frog into a prince: Effective schools research, policy, and practice at the district level. Harvard Educational Review, 54(2), 129-151.

DeYoung, A. J. (1994, January). Researching rural American schools: Continuing cultural themes and cultural conflicts in the countryside. Lexington: Appalachian Center at Kentucky University.

Glass, T. E. (1991). Research perspectives on the superintendency 1990. Arlington, VA: American Association of School Administrators.

Glass, T., Bjork, L., \& Brunner, C. (2000). The 2000 study of the American school superintendency: A look at the superintendent of education in the new millennium. Arlington, VA: American Association of School Administrators.

Grady, M. L., \& Bryant, M. T. (1991a). School board turmoil and superintendent turnover: What pushes them to the brink? School Administrator, 48(2), 19-26.
Grady, M. L., \& Bryant, M. T. (1991b). A study of frequent superintendent turnover in a rural school district: the constituents' perspective. Journal of Rural and Small Schools, 3(4), 10-13.

Greenfield, W. (1995, February). Toward a theory of school administration: the centrality of leadership. Educational Leadership Quarterly, 31, 61-85.

Haas, T. (1991). Why reform doesn’t apply. In A. J. DeYoung (Ed.), Rural educational issues and practice. New York: Garland.

Herzog, M. J. R., \& Pittman, R. (1999). The nature of rural schools: trends, perceptions and values. In D. M. Chalker (Ed.), Leadership for rural schools: Lessons for all. Lancaster, PA: Technomic Publishing Co.

Holmes, N. C. (1991). Consolidate, cooperate, or collaborate: Dilemmas of rural schools. In M. Fitzmaurice, Spotlight on rural schools in New Jersey: A directory of effective programs, practices, and resources for rural educators. Philadelphia: Research for Better Schools.

Jacobson, S. L. (1988a). The rural superintendency: Reconsidering the administrative farm system. Research in Rural Education, 2(5), 37-42.

Jacobson, S. L. (1988b). Effective superintendents of small, rural districts. Journal of Rural and Small Schools, 2(2), 17-21.

Kadamus, J. A. (2002, April 10). Creating a framework for the preparation of school leaders [Memo to the members of the Board of Regents of New York State].

Keeney, L., \& Devaney, K. (Eds.). (1982). Four workparties focus on rural education. San Francisco: Far West Laboratory for Educational Research and Development: Teachers' Center Exchange.

Krueger, R., \& Casey, M. A. (2000). Focus groups. Thousand Oaks, CA: Sage.

Leach, E. L. (1991, October). Rural school administrators for a new age. Paper presented at the 83rd annual conference of the National Rural Education Association, Jackson, MS.

Leithwood, K., \& Montgomery, D. J. (1986). The principal profile. Toronto: Ontario Institute for Studies in Education.

Manasse, A. L. (1985). Vision and leadership: paying attention to inattention. Peabody Journal of Education, 63(1), 150-173.

Musella, D., \& Leithwood, K. (1988). The influence of chief education officers on school effectiveness. Peabody Journal of Education, 65(4), 90-112. 
New York State Council of School Superintendents and the Membership Committee (NYSCOSS).

(2001, March). Snapshot 2000: a study of school superintendents in New York State. Albany.

Peterson, K. D. (1984). Mechanisms of administrative control over managers in educational organizations. Administrative Science Quarterly, 29(4), 573-597.

Peterson, K. D., Murphy, J., \& Hallinger, P. (1987). Superintendent perceptions of the control and coordination of the technical core in effective school districts. Educational Administrative Quarterly, 18(1), 79-95.

Sher, J. P., \& Rosenfeld, S. A. (1977). Public education in sparsely populated areas of the United States. Washington, DC: National Institute of Education.

Silky, W. (2003, January). Personal communication.

Stephens, E. R., \& Turner, W. G. (1988). Leadership for rural schools. Arlington, VA: American Association of School Administrators.

Tagg, G. J. (1982). The trials and tribulations of a rural superintendent. Paper presented at the annual convention of the American Association of School Administrators, New Orleans.

Tift, C. (1990). Rural administrative leadership handbook. Portland, OR: Northwest Regional Educational Lab.

Wallin, D. C. (1999). Succession management: A necessary strategy for rural school administrators. Opinion paper delivered at University of Saskatchewan.

Wilson, A. P., \& Heim, J. M. (1985).

Administrative turnover in Kansas rural school districts: 1978-1984. Research in Rural Education, 3(1), 19-22. 